Weitere Leistungen, die über das notwendige Maß hinausgehen, sind sogenannte Zusatzleistungen, $\int 88$ SGB I. Nach dem SGB XI gibt es Zusatzleistungen im Bereich

- Unterkunft und Verpflegung und/oder bei

- pflegerisch-betreuenden Leistungen.

Die Abgrenzung zwischen Regelleistung und Zusatzleistung wird in den Rahmenverträgen der Länder leider oft nur unzureichend geregelt. Friseurbesuch und chemische Reinigung dürften zum Beispiel in allen Bundesländern Zusatzleistungen sein.

\section{Resümee}

Die unterschiedlichen Kosten sind für die Betroffenen und die Solidargemeinschaft der Versicherten im Einzelnen weder nachvollziehbar noch überprüfbar. Deshalb fordert die Kommission Ältere Menschen des djb mehr Transparenz in allen Bereichen. Das ist ein Gebot des Rechtsstaatsprinzips. Es ist unverständlich, dass die Bundesregierung bislang ihrer Ver-

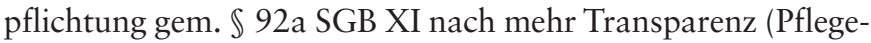
heimvergleich) durch Erlass der vorgesehenen Rechtsverordnung noch nicht nachgekommen ist.

\title{
Europawahl am 7. Juni 2009 - Gehen Sie wählen?!
}

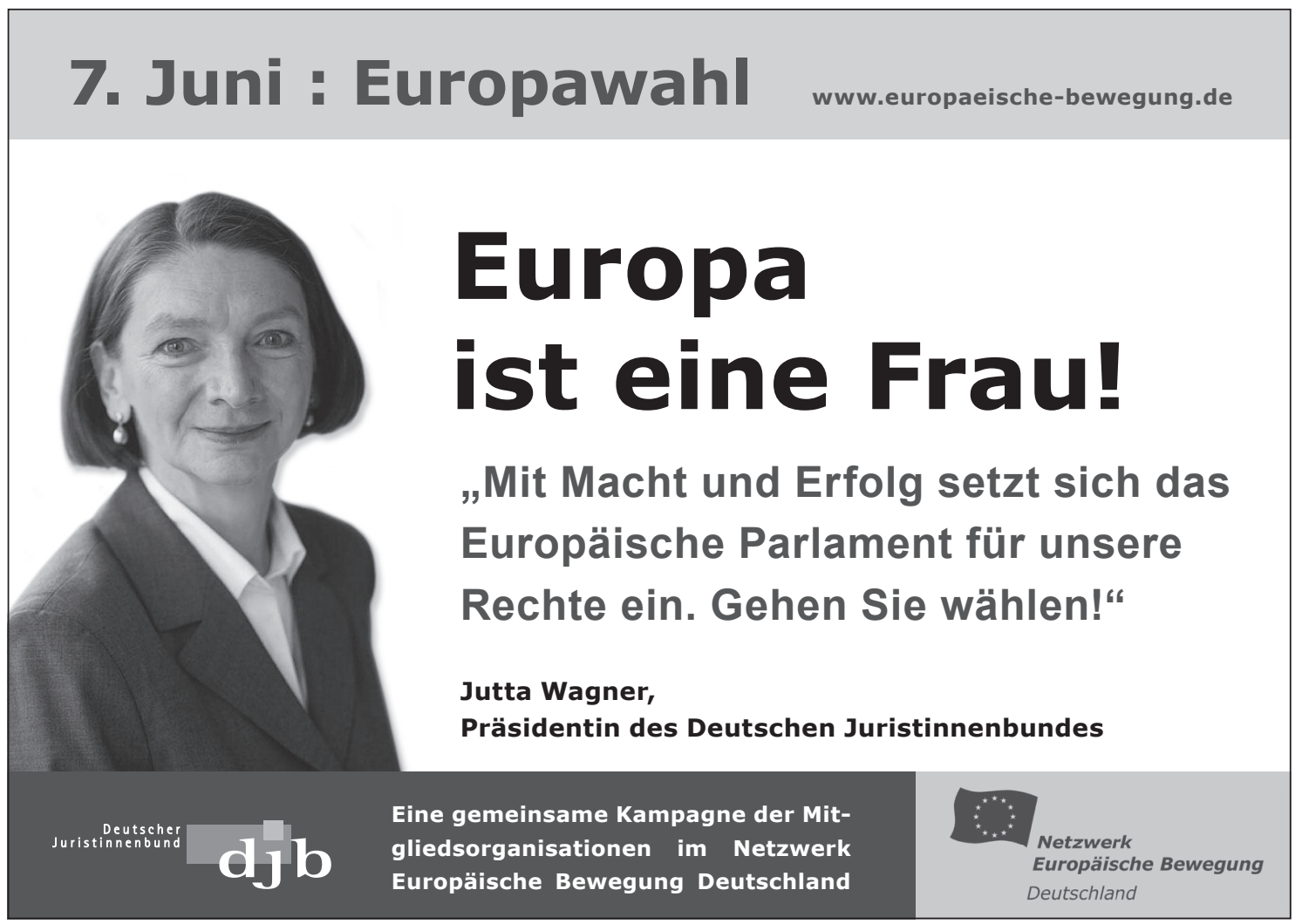

„Das Europäische Parlament hat nichts zu entscheiden. Es vertritt die Interessen der Wirtschaft. Und überhaupt mischt sich Europa überall ein, ob es darf oder nicht.“ Wer so denkt, tut gut daran, nicht zur Wahl zu gehen.

Wer allerdings gut informiert ist, geht wählen. Fast alle Entscheidungen in Europa können nur mit dem Europäischen Parlament überhaupt getroffen werden. Auch auf die Inhalte nehmen die Europaabgeordneten erheblichen Einfluss und greifen die Interessen der Bürgerinnen und Bürger auf. Ein gutes Beispiel dafür ist die Dienstleistungsrichtlinie. Unser djbSeminar hierzu zeigte deutlich, wie aus dem ursprünglich rein wirtschaftsorientierten Kommissionsentwurf ein Rechtsakt wurde, der Belange des Verbraucherschutzes ebenso berücksichtigt wie soziale Belange. Die Gleichstellung der Geschlech- ter ist ein weiteres Politikfeld, das sich durch den Einfluss des Europäischen Parlamentes dynamisch entwickelt hat. Europa darf und soll sich einmischen, wenn es geboten ist. Ein Europa - in Vielfalt geeint - nützt allen und braucht gemeinsame Regeln. Am 7. Juni haben wir die Chance, unser Europa mitzugestalten.

Deshalb engagiert sich der djb bei der Wahlaufruf-Kampagne des Netzwerkes Europäische Bewegung Deutschland (www.europaeische-bewegung.de).

\section{EUROPA ist eine Frau!}

Mit Macht und Erfolg setzt sich das Europäische Parlament für unsere Rechte ein - Gehen Sie wählen!“ 